\title{
BISE - Call for Papers Issue 01/2013
}

\section{Mobile and Ubiquitous Solutions for Health Care of the Future}

DOI 10.1007/s12599-011-0164-6

\author{
The Authors \\ Prof. Dr. Stefan Kirn ( $\varangle)$ \\ University of Hohenheim \\ Schwerzstr. 35 \\ 70599 Stuttgart \\ Germany \\ stefan.kirn@uni-hohenheim.de
}

Prof. Nilmini Wickramasinghe,

Ph.D., MBA

School of Business IT and Logistics

RMIT University

GPO Box 2476

Melbourne, VIC 3001

Australia

nilmini.wickramasinghe@rmit.edu.au

Published online: 2011-07-13

This article is also available in German in print and via http://www. wirtschaftsinformatik.de: Kirn S, Wickramasinghe $\mathrm{N}$ (2011) WI - Call for Papers Heft 01/2013. Mobile und ubiquitäre Lösungen für das Gesundheitswesen der Zukunft. WIRTSCHAFTSINFORMATIK. doi: 10.1007/s11576-0110276-0.

(C) Gabler Verlag 2011

\section{Special Focus}

The application of innovative, mobile, and ubiquitous technology is important not only for coordination, organization, and administration of medical processes, but may also be lifesaving in context of medical care. Imaginable for the future is the physician's access to a patient's health record directly at the scene of an accident, or an "App" warning an asthmatic, if his physical strain is too high. So-called "heart phones" are already in use today. Heart patients can record at any time an ECG with their mobile phone and send it to their cardiologist. With all these ap- plications more safety for physicians and patients through a faster work flow can be achieved.

Besides medical applications, an improvement of coordination, organization, and administration of the processes are possible. Applications like patient tracking or the use of a mobile, rule-based anamnesis system help to get more transparency in patient treatment process, help to prevent unnecessary examinations, and help to provide data of high quality more quickly. From patients' view needless physical and mental stress caused by long waiting times or multiple examinations can be avoided. Furthermore it's possible to reduce loss of quality caused by avoidable additional work of physicians and nursing staff.

Meanwhile, these developments are tightly coupled with important trends like the Internet of things, teletrust, eidentity, reliable and trustworthy public telematics infrastructures and the creation of electronically interlocked processes within the healthcare sector, and between healthcare and public administration.

Against this background the use of mobile and ubiquitous applications is a basic instrument to increase process transparency and fasten the flow of information in order to improve patient care and reduce health care costs. But the users' willingness to accept and actively use these new and innovative solutions is required.

For stimulating and further deepen the discussion between science and practice, the journal Business \& Information Systems Engineering (BISE) addresses a special issue about "mobile and ubiquitous solutions for health care of the future". Collecting present developments, new methods and technologies including their application in the field of mobile and ubiquitous applications and evaluating their suitability for the future is the aim.
Contributions from research and business practice on the following (and related) topics are welcome:

- Innovations and change management

- Acceptance of technology

- Health telematics

- Electronic health card, and health professional card

- Data security and safety aspects

- Developments und Best Practices both national and international

- Transfer of success strategies from industry to health care

- Further issues in the field of mobile and ubiquitous applications

\section{Submission}

Please submit papers for the sections BISE - Research Paper and BISE - State of the Art by 2012-03-01 at the latest via the journal's online submission system (http://www.editorialmanager.com/buis/). Please observe the instructions regarding the format and size of contributions to Business \& Information Systems Engineering (BISE)/WIRTSCHAFTSINFORMATIK. Papers should not exceed 50,000 characters including spaces, minus 5,000 characters per page for illustrations. Detailed authors' guidelines can be downloaded from http://www.bise-journal.org.

All papers will be reviewed anonymously (double-blind process) by several referees with regard to relevance, originality, and research quality. In addition to the editors of the journal, including those of this special focus, distinguished national and international professionals with scientific and practical backgrounds will be involved in the review process.

Complementary articles covering topics of this special focus are also more than welcome.

Accepted papers will appear identically in English and German. The Englishlanguage version will appear in Business \& Information Systems Engineer- 
ing (BISE), the German-language version will appear in WIRTSCHAFTSINFORMATIK. Accepted papers will be translated in close cooperation with the authors and a professional team of translators.

\section{Schedule}

Submission deadline: 2012-03-01

Author notification: 2012-04-26

Completion of first revision: 2012-06-28

Author notification: 2012-08-16
Completion of a second revision (if needed, monolingual): 2012-09-20 Completion of a second revision (if needed, bilingual): 2012-10-18

Planned publication date of Issue 01/2013: February 2013 


\section{COMMERZBANK}

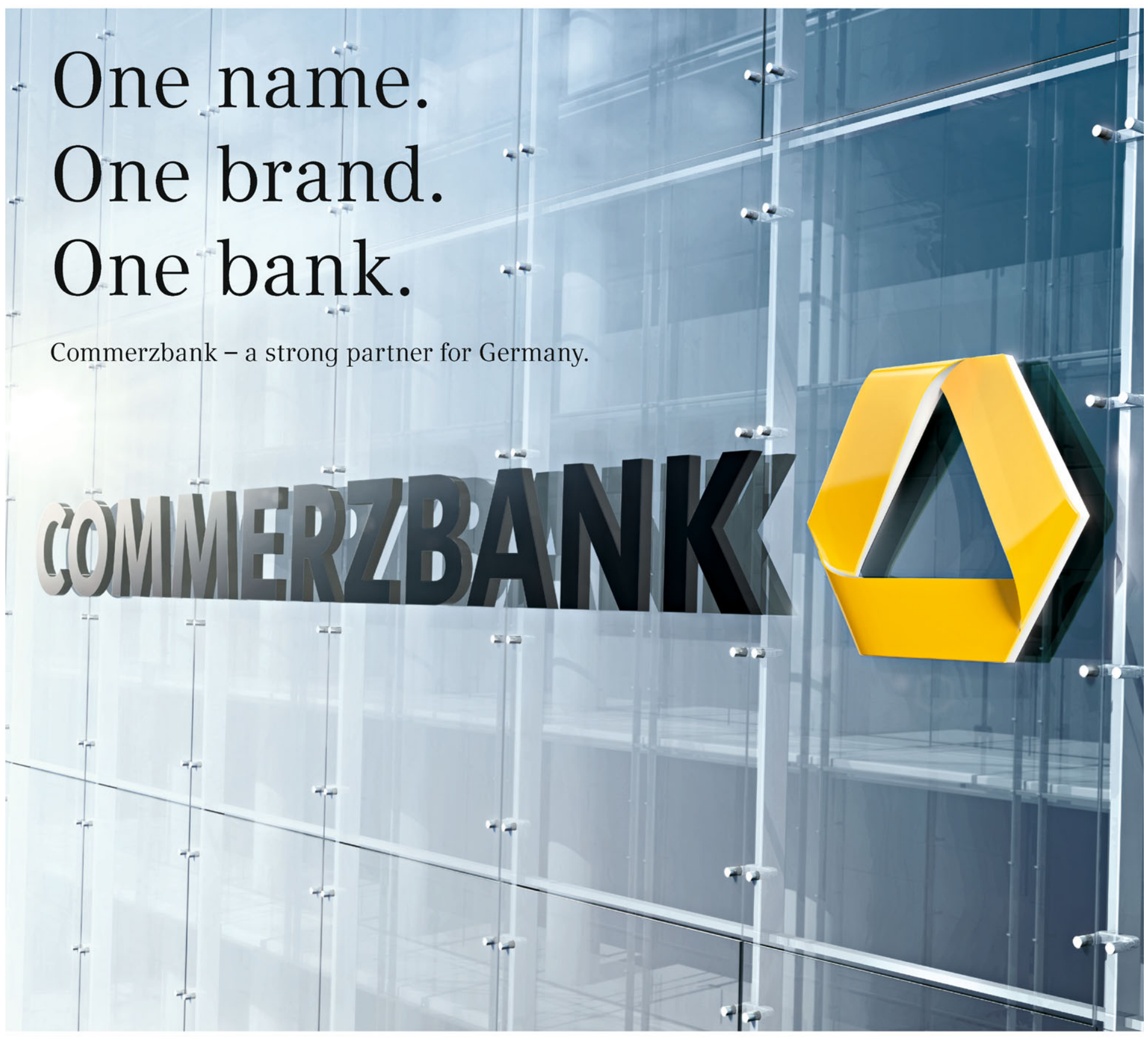

The new Commerzbank unites the strengths of Commerzbank and Dresdner Bank. As the leading bank for retail and corporate clients in Germany, we combine strong local links and a long tradition with the end-to-end expertise and power of an international network. In this way, we live our core values of partnership and performance: in our dealings with clients, investors and employees, and in providing outstanding quality and service. This makes us a reliable, strong long-term partnerGermany's bank of choice. www.commerzbank.com 


\section{0 0010000001010100 0111001001100001 0110100101101110 0110010101100101}

Sie sehen hier mehr als Nullen und Einsen?

Wir sehen Ihre Karriere im Traineeprogramm IT. Als spätere Fach- oder Führungskraft.

www.perspektiven.allianz.de

\section{Allianz (11)}




\section{McKinsey\& Company}

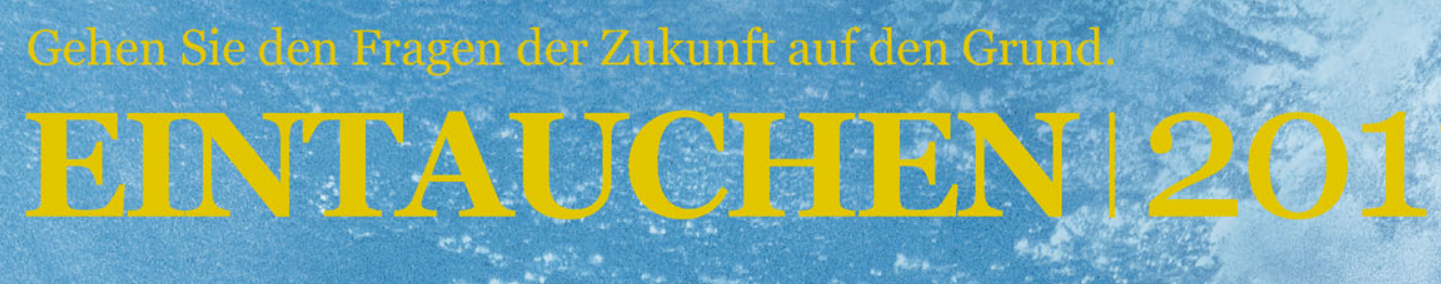

Vom 13. bis 16. Oktober 2011 in tïssabon. Eintauchen 2011 - das Mckinsey-Seminar für Doktoranden und Studenten, die sich für Business und Technologie begeiste rn.

Welche IT-Strategie benötigt eine Krankenkasse, um ihren Versicherten die bestmögliche Versorgung zukommen zu lassen? Wie muss sie dabei mit Herausforderungen wie knappen Mitteln, alternder Bevölkerung und zunehmender Verbreitung chronischer Krankheiten umgehen? Gewinnen Sie in einer spannenden Fallstudie Einblicke in die vielfaltigen Tätigkeitsfelder des Business Technology Office. Lernen Sie die Menschen kennen, die McKinsey ausmachen, und erfahren Sie alles über Thre persönlichen Einstiegsmöglichkeiten und Karrierechancen.

Bewerben Sie sich bis zum 28. August 2011 unter www.eintauchen.mckinsey.de.

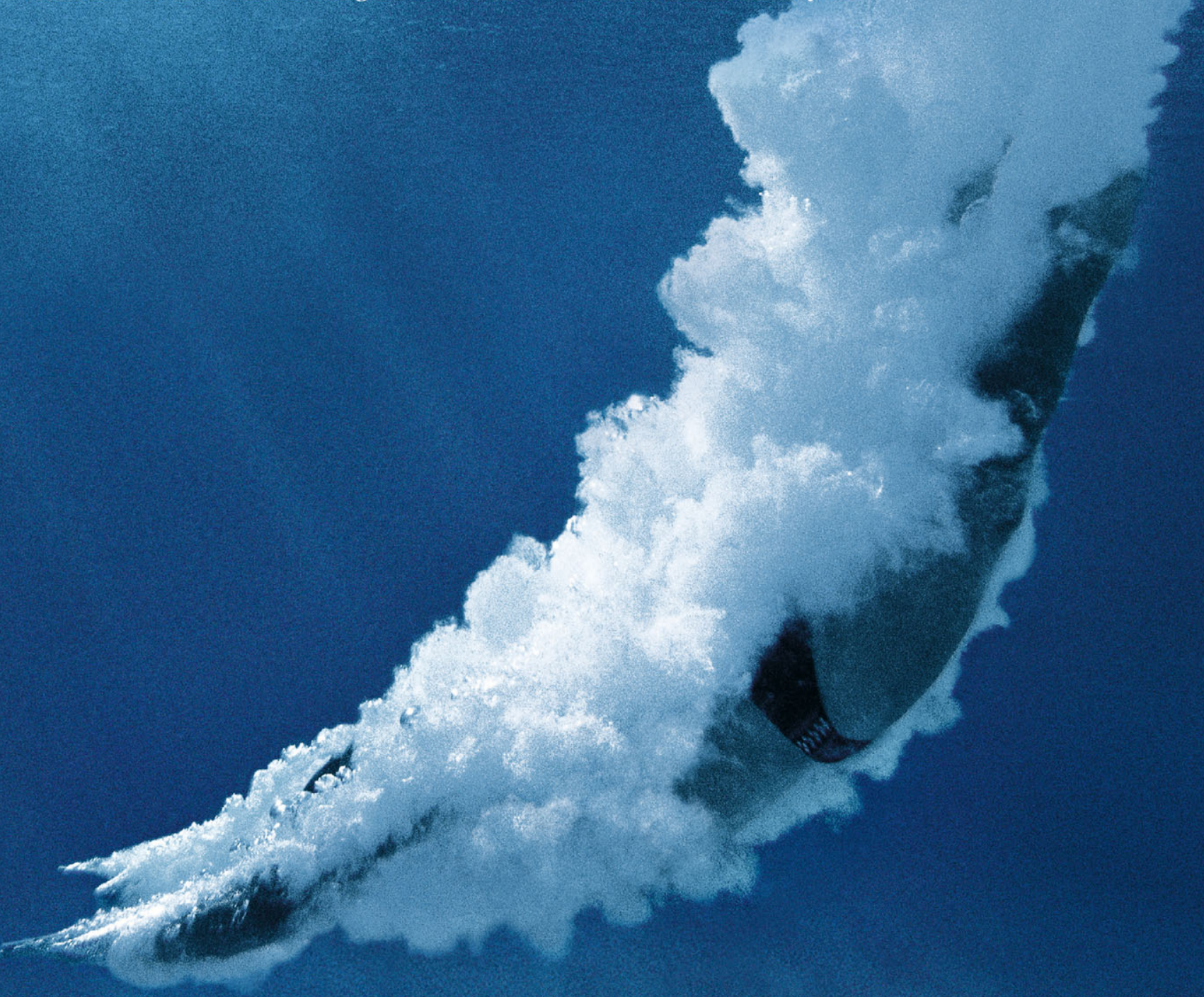




\section{Strategic International Management in 20 lessons on key issues}

WWW.GABLER.DE

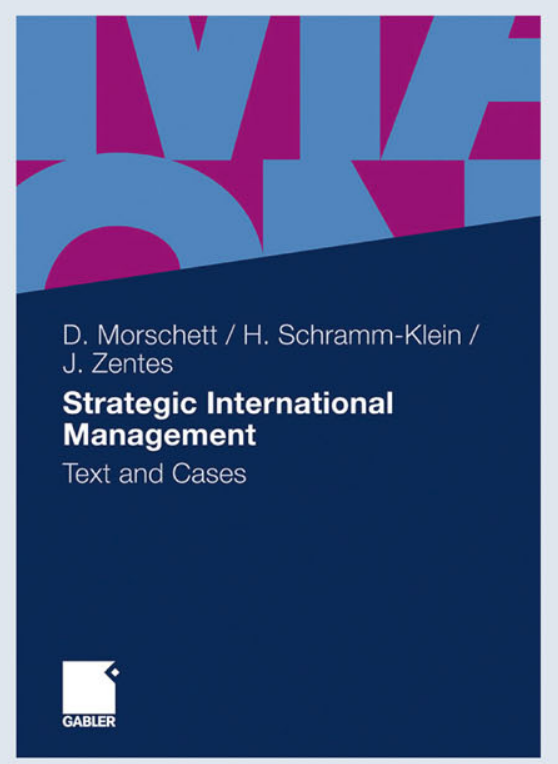

Dirk Morschett / Hanna Schramm-Klein / Joachim Zentes

\section{Strategic International Management}

Text and Cases

2. Ed. 2010. X, 470 pp. Softc. EUR 42,00

ISBN 978-3-8349-2535-0

„Strategic International Management“ takes a global perspective and covers the major aspects of international business strategies, the coordination of international companies and the particularities of international value chain activities and management functions. The book provides a thorough understanding of how Production \& Sourcing, Research \& Development, Marketing, Human Resource Management and Controlling have to be designed in an international company and what models are available to understand those activities in an international context.

The book offers 20 lessons that provide a comprehensive overview of all key issues. Each lesson is accompanied by a case study from an international company to facilitate the understanding of all important factors involved in strategic international management.

In this second edition, all chapters have been updated, all case studies revised and recent data were integrated. The concept, though, remained unchanged.

\section{Content}

- Introduction to Strategic International Management

- The External Environment

- International Coordination

- Foreign Operation Modes

- Selected Value Chain Activities

- Selected International Business Functions

\section{The Authors}

Dirk Morschett is Professor of International Management at the University of Fribourg, Switzerland. He holds the Liebherr/Richemont Endowed Chair for International Management and is responsible for the Master of Arts in European Business at the University of Fribourg. Hanna Schramm-Klein is Professor of Marketing at the University of Siegen, Germany. She holds a Chair for Marketing and teaches International Marketing, Marketing and International Management at the University of Siegen and in different MBA programmes.

Joachim Zentes is Professor of Management and Marketing at the Saarland University, Saarbrücken, Germany. He is Director of the H.I.MA. (Institute for Commerce \& International Marketing) and Director of the Europa-Institut at Saarland University. He holds a Chair in Business Adminstration, with a focus on Foreign Trade and International Management. 


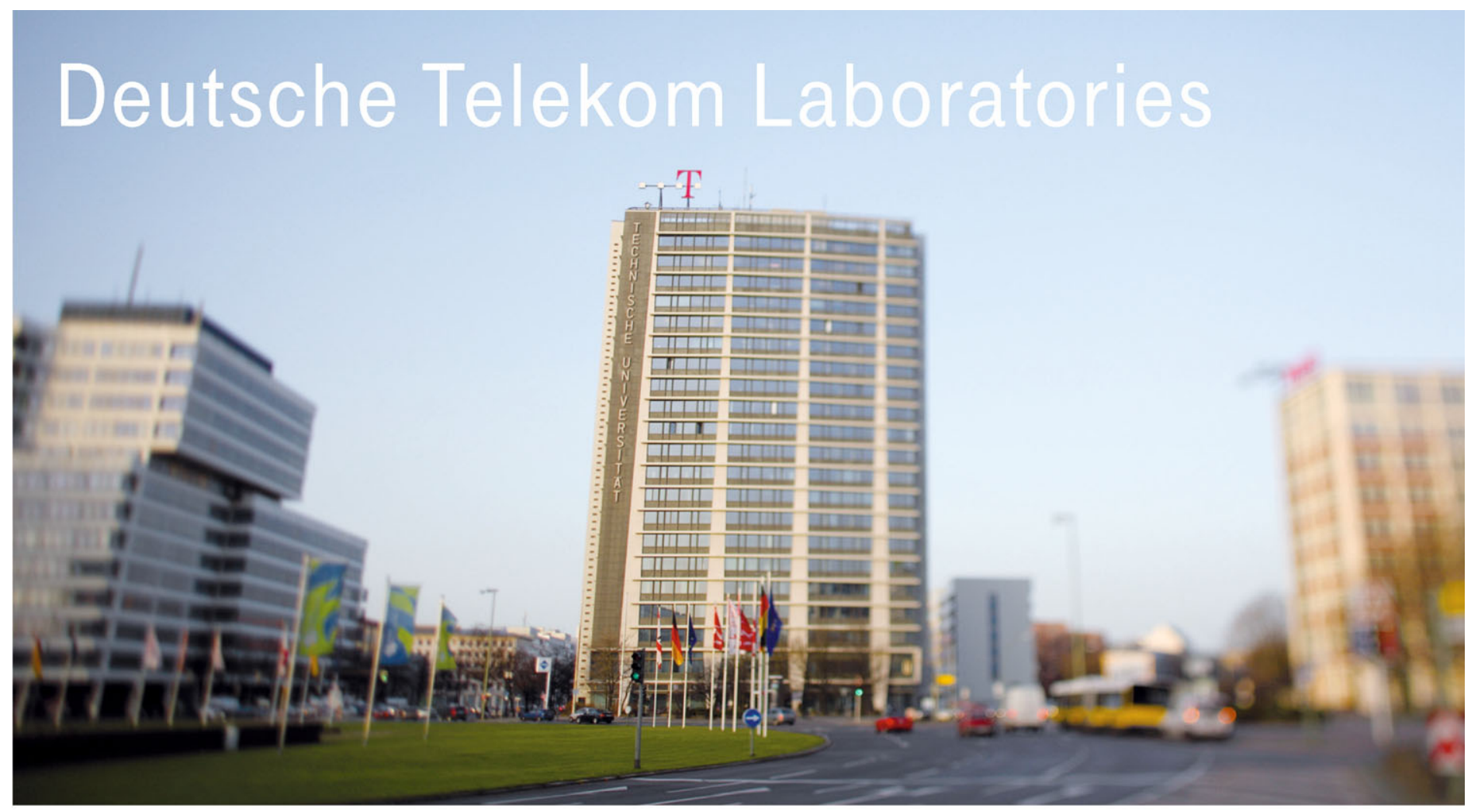

\section{We shape the future}

Deutsche Telekom Laboratories are Telekom's research and development institute. Established under private law, this scientific facility is an affiliated institute of the renowned Technische Universität (TU) Berlin. At Telekom Laboratories, some 360 scientists from around the world and experts from the Telekom Group develop new, innovative services and solutions for the Group's customers. The founding of new start-up companies is another way the Group utilizes Telekom Laboratories' results.

Cooperation with the TU Berlin, the Berlin University of the Arts, other universities and industry partners creates a bridge between business and science in order to turn ideas into marketable innovations as quickly as possible. Telekom Laboratories' innovative processes are based on "open innovation" principles that enable the free exchange of ideas and information between selected institutions and companies. The objective is to capture synergy effects and to continue enhancing research results, as quickly and efficiently as possible, through interchange. This also encompasses the inclusion of users and customers in the innovation process, as enabled by a number of inventive methods.

Telekom Laboratories pursues two main approaches with its activities: On the one hand, it supports the development of applications and services, for example, in the fields of connected home, healthcare, automotive, smart grid, mobile payment and new interactive media. On the other, it safeguards Telekom's future infrastructure with its ideas and developments, for example, in the area of fiber-optic networks, future mobile communications technologies, cloud computing and the Internet of the future.

The business and information systems engineering offers useful interdisciplinary approaches for these key topics. Subject matter includes, for example, modeling, methods and tools for process innovations, agile architectures for information and communication technologies (ICT), technology-oriented management approaches and techno-economic assessments. The aim is to safeguard the economic sustainability of innovations for the Group.

Telekom Laboratories is divided into two areas: The Innovation Development Laboratory focuses on near-market developments with a time horizon of 18 months to three years. In the Strategic Research Laboratory, scientists holding seven professorships work on long-term technology and applied research.

Aside from its Berlin headquarters, Telekom Laboratories also operate facilities in Darmstadt (Germany), Beer Sheva (Israel) and Los Altos (United States).

Contact:

Deutsche Telekom Laboratories Ernst-Reuter-Platz 7, 10587 Berlin E-mail:wi.laboratories@telekom.de www.laboratories.telekom.com

\section{Deutsche Telekom Laboratories}

An-Institut der Technischen Universität Berlin 


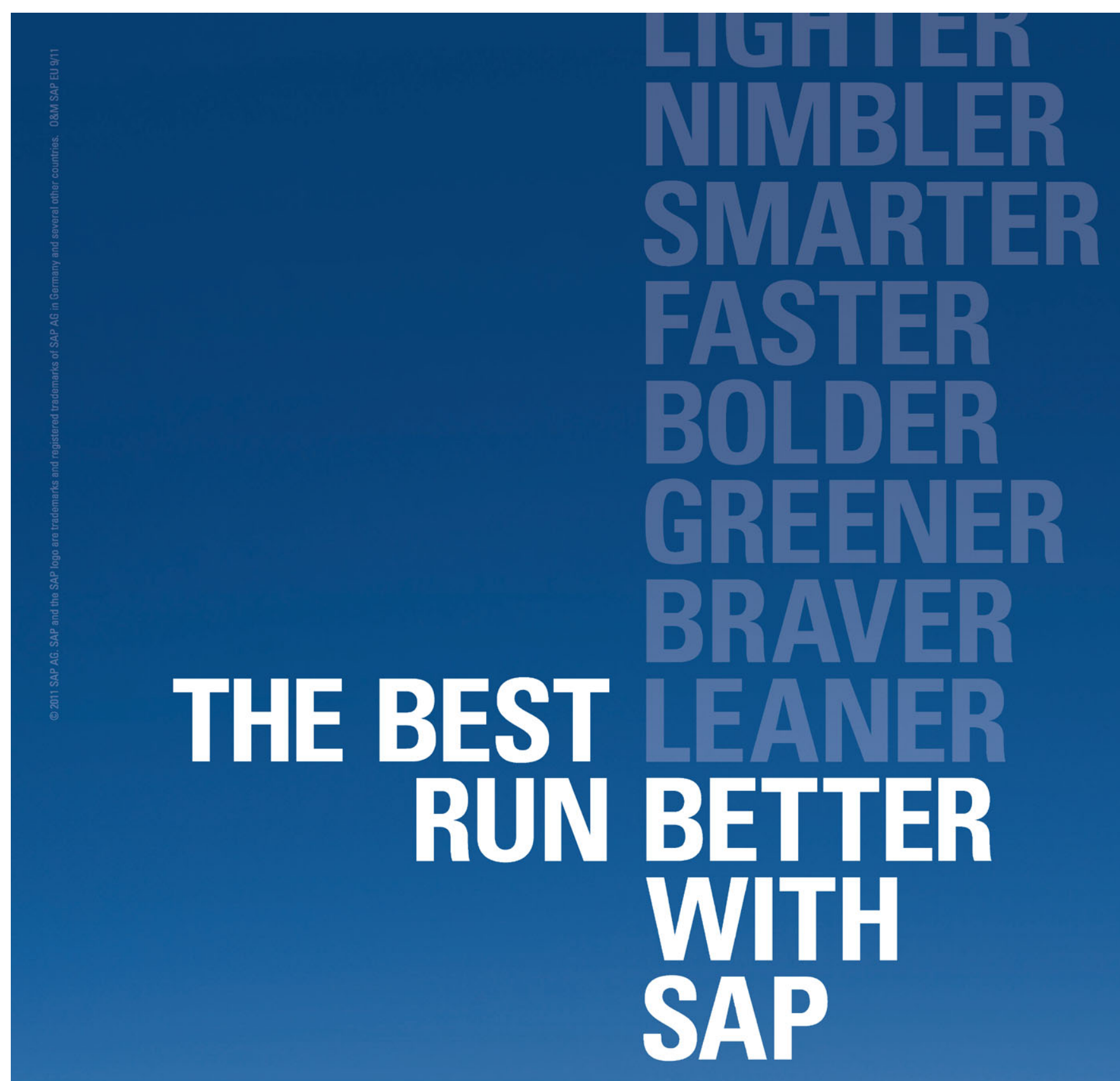

\section{SAP HELPS THE WORLD'S GREATEST COMPANIES DO WHAT THEY DO BEST, EVEN BETTER.}

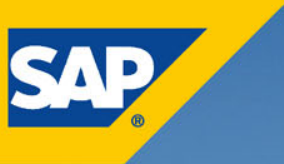

Whether helping companies

out-compete, out-innovate, out-serve

or out-transform their competitors,

SAP has but one goal - to make every

business a best-run business.

Our software is designed for it.

Our company revolves around it.

Our people are obsessed with it.

Find out what SAP can do for your

business at sap.com/better 